\title{
Identification and characterization of the zinc-regulated transporters, iron-regulated transporter-like protein (ZIP) gene family in maize
}

Suzhen $\mathrm{Li}^{1,2+}$, Xiaojin Zhou ${ }^{2 \dagger}$, Yaqun Huang ${ }^{1}$, Liying Zhu' ${ }^{1}$, Shaojun Zhang ${ }^{2}$, Yongfeng Zhao ${ }^{1}$, Jinjie Guo ${ }^{1}$, Jingtang Chen ${ }^{1 *}$ and Rumei Chen ${ }^{2^{*}}$

\begin{abstract}
Background: Zinc (Zn) and iron (Fe) are essential micronutrients for plant growth and development, their deficiency or excess severely impaired physiological and biochemical reactions of plants. Therefore, a tightly controlled zinc and iron uptake and homeostasis network has been evolved in plants. The Zinc-regulated transporters, Iron-regulated transporter-like Proteins (ZIP) are capable of uptaking and transporting divalent metal ion and are suggested to play critical roles in balancing metal uptake and homeostasis, though a detailed analysis of ZIP gene family in maize is still lacking.
\end{abstract}

Results: Nine ZIP-coding genes were identified in maize genome. It was revealed that the ZmZIP proteins share a conserved transmembrane domain and a variable region between TM-3 and TM-4. Transiently expression in onion epidermal cells revealed that all ZmZIP proteins were localized to the endoplasmic reticulum and plasma membrane. The yeast complementation analysis was performed to test the Zn or Fe transporter activity of ZmZIP proteins. Expression analysis showed that the ZmIRT1 transcripts were dramatically induced in response to Zn- and Fe-deficiency, though the expression profiles of other ZmZIP changed variously. The expression patterns of ZmZIP genes were observed in different stages of embryo and endosperm development. The accumulations of ZmIRT1 and ZmZIP6 were increased in the late developmental stages of embryo, while ZmZIP4 was up-regulated during the early development of embryo. In addition, the expression of ZmZIP5 was dramatically induced associated with middle stage development of embryo and endosperm.

Conclusions: These results suggest that ZmZIP genes encode functional Zn or Fe transporters that may be responsible for the uptake, translocation, detoxification and storage of divalent metal ion in plant cells. The various expression patterns of ZmZIP genes in embryo and endosperm indicates that they may be essential for ion translocation and storage during differential stages of embryo and endosperm development. The present study provides new insights into the evolutionary relationship and putative functional divergence of the ZmZIP gene family during the growth and development of maize.

Keywords: Embryo, Endosperm, Expression profiling, Zinc, Iron, Zinc-regulated transporters, Iron-regulated transporter-like protein (ZIP), Subcellular localization, Yeast complementation, Maize

\footnotetext{
* Correspondence: chenjingtang@126.com; chenrumei@caas.cn

${ }^{\dagger}$ Equal contributors

'Department of Agronomy, Agricultural University of Hebei/Hebei Sub-center

of Chinese National Maize Improvement Center, Baoding 071001, China

2Department of Crop Genomics \& Genetic Improvement, Biotechnology

Research Institute, Chinese Academy of Agricultural Sciences, Beijing 100081,

China
}

\section{Biomed Central}

(c) 2013 Li et al.; licensee BioMed Central Ltd. This is an Open Access article distributed under the terms of the Creative Commons Attribution License (http://creativecommons.org/licenses/by/2.0), which permits unrestricted use, distribution, and reproduction in any medium, provided the original work is properly cited. 


\section{Background}

Zinc and iron are essential for plant metabolism and development [1]. Zinc serves as a key structural motif in many proteins, including DNA-binding Zn-finger protein [2,3], RING finger proteins and LIM domain containing proteins [4], which play vital roles in controlling cellular processes such as growth, development and differentiation. An adequate $\mathrm{Zn}$ content enhances crop productivity [5]. Iron plays an important role in electron transfer in photosynthesis and respiration, though high concentration of intracellular iron may lead to elevated $\mathrm{Fe}^{3+} / \mathrm{Fe}^{2+}$ redox reactions and cause damage [6]. The deficiency of $\mathrm{Zn}$ and Fe decreases plant growth and affecting cereal production and grain quality [7], but excess Zn and Fe may cause significant toxicity to biological systems $[8,9]$. Therefore, plants have established a tightly controlled system to balance the uptake, utilization and storage of these metal ions $[10,11]$. Because $\mathrm{Zn}$ cannot diffuse across cell membrane, specific zinc transporters are required to transport $\mathrm{Zn}$ into cytoplasm [12,13]. In recent years, a number of metal transporters have been identified in plants, including the $\mathrm{P}_{1 \mathrm{~B}}$-ATPase family, zinc-regulated transporter (ZRT), iron-regulated transporter (IRT)-like protein (ZIP), natural resistance-associated macrophage protein (NRAMP) family, and cation diffusion facilitator (CDF) family [14].

ZRT, IRT-like protein (ZIP) family has been characterized ubiquitously in organisms, including archaea, bacteria, fungi, plants and mammals, and has been demonstrated to be involved in metal uptake and transport [11]. ZIP proteins generally contribute to metal ion homeostasis by transporting cations into the cytoplasm [14]. Functional complementation in yeast indicated that ZIP proteins are able to transport various divalent cations, including $\mathrm{Fe}^{2+}$, $\mathrm{Zn}^{2+}, \mathrm{Mn}^{2+}$, and $\mathrm{Cd}^{2+}$ [15]. The ZIP proteins consist of 309-476 amino acid residues with eight potential transmembrane domains and a similar membrane topology. There is also a variable region between TM-3 and TM-4, in which the amino- and carboxyl-terminals located on the outside surface of plasma membrane. The variable region contains a potential metal-binding domain rich in conserved histidine residues [15]. Several ZIP proteins have been identified in Arabidopsis [16]. AtIRT1 (Iron-regulate transporter 1) was the first member to be identified through functional complementation of a yeast mutant defective in iron uptake, and it encodes a major Fe transporter at the root surface in Arabidopsis [17-20]. Further analysis showed that the irt1 mutant exhibited lethal chlorotic phenotypes [18-20], and had lower $\mathrm{Ni}$ accumulation under Fe-deficient conditions than the wild type plants. These results indicated that AtIRT1 mediates $\mathrm{Fe}$ and $\mathrm{Ni}$ translocation in Arabidopsis [21]. Likewise, overexpressing AtIRT3 leads to increased accumulation of $\mathrm{Zn}$ in shoots and Fe in roots. Moreover, AtIRT3 could complement the
$\mathrm{Zn}$ and $\mathrm{Fe}$ uptake double yeast mutants, indicating that AtIRT3 is involved in $\mathrm{Zn}$ and Fe translocation [22]. Besides, expression analysis revealed that the transcripts of AtZIP1 to AtZIP5, AtZIP9 to AtZIP12, and AtIRT3 were increased in response to Zn-deficiency, suggesting that they may enhance $\mathrm{Zn}$ acquisition under deficient $\mathrm{Zn}$ status in Arabidopsis [23]. In rice, overexpression of OsIRT1 leads to increased $\mathrm{Fe}$ and $\mathrm{Zn}$ accumulations in shoots, roots and mature seeds, suggesting OsIRT1 is a functional metal transporter for iron, and it is responsible for the absorption of iron from soil, especially under Fe-deficiency [24-26]. On the contrary, over accumulation of OsZIP4 and OsZIPS cannot increase the $\mathrm{Zn}$ content in seeds, though the $\mathrm{Zn}$ concentration in roots were dramatically increased in transgenic plants $[27,28]$. These results indicated that maintaining the endogenous expression pattern of $Z I P$ genes may be essential for $\mathrm{Zn}$ translocation in plants. Likewise, overexpression of TdZIP1, a $\mathrm{Zn}$ transporter from wild emmer wheat, causes excess accumulation of $\mathrm{Zn}$ in cells, thus generating a toxic cytosolic environment [29]. Therefore, increase $\mathrm{Zn}$ content by transgenic approaches may benefit from elucidating the expression pattern of ZIP genes.

Since ZIP is the key transporter for $\mathrm{Zn}$ and Fe uptake and translocation in plants, considerable progress has been achieved in cloning and characterizing its functions in crop plants, including soybean and maize [30,31]. The soybean GmZIP1 is highly selective for $\mathrm{Zn}$, and it might play a role in the symbiotic relationship between soybean and Bradyrhizobium japonicum [30]. The ZmZLP1 (ZmZIP-like protein) was identified from a cDNA library of Zea mays L. (maize) pollen. It was reported that ZmZLP1 localized to the endoplasmic reticulum and may be responsible for transporting zinc from the ER to the cytoplasm, though its physiological function has not been characterized [31]. The maize genome has been thoroughly sequenced and assembled. However, systematic analysis of the maize ZIP gene family is still limited. In the present study, we provide detailed information on the gene identification, chromosomal locations, subcellular localizations and expression patterns of nine $Z m Z I P$ genes. In addition, the transporter activities of ZmZIPs were tested by yeast complementation analysis. Our results suggest that $Z m Z I P$ genes may be responsible for the uptake and translocation of $\mathrm{Zn}$ or $\mathrm{Fe}$ and involve in detoxification and storage of metals in plant cells, as well as embryo and endosperm development.

\section{Results}

\section{Cloning of ZmZIP genes and phylogenetic analysis}

Extensive searches of public genomic databases, by using reported ZIP proteins from rice as TBLASTN queries, identified a total of nine maize ZIP genes that have complete sequences. Nine cDNA fragments containing complete 
opening reading frame (ORF) were cloned from leaf tissues of maize (Zea mays inbred line X178) by RT-PCR, and they were designated as ZmZIP1-8 and ZmIRT1 according to the amino acid sequence similarity with the rice and Arabidopsis (Table 1). The predicted proteins of ZmZIPs consist of 359-490 amino acids, and harbour 6-9 putative transmembrane (TM) domains. In addition, there was a variable region between TM-3 and TM-4, containing a potential metal-binding domain rich in histidine residues (Figure 1). The phylogenetic analysis showed that ZmZIP1 was closely related to AtIAR1 and OsIAR1; ZmIRT1 was related to HvIRT1 and resided in a branch comprised by iron transporter OsIRT1 and OsIRT2. It was suggested that the amino acid residue D100 in AtIRT1 is responsible for Fe and Mn transport [22], and it is conserved in ZmIRT1 (Additional file 1), which indicates that ZmIRT1 may be functional related to a Fe transporter. In addition, ZmZIP3 and ZmZIP4 formed a gene cluster with OsZIP3 and OsZIP4; ZmZIP2 was most closely related to OsZIP2 in the other branch comprised by zinc transporters OsZIP1, AtZIP2 and AtZIP11; ZmZIP5 and ZmZIP7 were observed in a branch; ZmZIP8 and ZmZIP6 were closely related to OsZIP8 and OsZIP6, respectively (Figure 2). These results revealed that $\mathrm{ZmZIPs}$ may be functional $\mathrm{Zn}$ or Fe transporters.

\section{Expression patterns of ZmZIP genes in different tissues of maize}

Recently, functional analysis has revealed that some ZIP genes in Arabidopsis and rice play important roles in transporting $\mathrm{Zn}$ or Fe $[26,27,32]$. To better understand the physiological functions of $Z m Z I P$ genes, their expression patterns in seedlings (under various metal conditions), embryo and endosperm were investigated by real-time RT-PCR. Under sufficient metal nutritional conditions, eight $Z m Z I P$ genes were mainly expressed in shoots, while $Z m I R T 1$ was accumulated abundantly in both shoots and roots (Additional file 2). In addition, the expression profiles of $Z m Z I P$ genes were determined in response to fluctuating divalent metal status. Under $\mathrm{Zn}$-deficient conditions, the expression levels of ZmIRT1, ZmZIP5 and $Z m Z I P 8$ were up-regulated in shoots at $96 \mathrm{~h}$, whereas $Z m Z I P 3$ was induced in both shoots and roots at $6 \mathrm{~h}$ (Figure 3). The accumulation of ZmIRT1 was gradually increased in response to $\mathrm{Zn}$-excess in shoots and reached the maximum level at $96 \mathrm{~h}$ after treatment, while that was suppressed in roots. Moreover, the expression of ZmZIP4, 5,7 and 8 were suppressed and decreased gradually in shoots, while ZmZIP3 was down-regulated remarkably in roots (Figure 3). These results indicated that $Z m I R T 1$, $Z m Z I P 3,4,5,7$ and 8 are sensitive to fluctuating environmental $\mathrm{Zn}$ status in seedlings.

Under Fe-deficient conditions, the expression of ZmIRT1 was dramatically up-regulated in shoots and roots. In response to Fe-excess, the transcript level of ZmIRT1 was suppressed in shoots and roots, while that of ZmZIP4, 5,7 and 8 were increased and reached to the maximum level at $96 \mathrm{~h}$ in both shoots and roots (Figure 3). These results indicated that $Z m I R T 1$ and $Z m Z I P 4,5,7,8$ are sensitive to environmental Fe conditions in shoots and roots. Under $\mathrm{Cu}$ - and $\mathrm{Mn}$-deficient conditions, the expression patterns of ZmZIP genes showed no obvious change (Additional file 3).

A detailed analysis of the transcriptional profiles of $Z m Z I P$ genes along embryo and endosperm development of maize were measured by real-time RT-PCR. Total RNA was isolated from embryo and endosperm on indicated days after pollination (DAP) (Figure 4A and 4B). The results revealed that the expression levels of $Z m Z I P 4$ and $Z m Z I P 5$ were up-regulated on 17 DAP, while $Z m I R T 1$ and $Z m Z I P 6$ were mainly expressed in the late developmental stages of embryo. Moreover, the expression of ZmZIP5 was dramatically increased associated with endosperm development and reached a peak on 19 DAP (approximately 50-fold higher than that of 11 DAP) (Figure 4A and 4B). Taken together, these results suggested that ZmIRT1, ZmZIP4 and ZmZIP6 may play important roles during embryo development in maize, while

Table 1 List of ZIP genes in the maize genome

\begin{tabular}{|c|c|c|c|c|c|c|}
\hline Gene name & Gene ID ${ }^{a}$ & NCBI accession & Chromosome & CDS length $^{\mathbf{b}}$ & Protein length & TM domains \\
\hline$Z m Z I P 1$ & LOC100192506 & NM_001137726 & 1 & 1473 & 490 & 7 \\
\hline$Z m Z I P 2$ & LOC100286282 & NM_001159169 & 2 & 1080 & 359 & 9 \\
\hline ZmZIP3 & LOC100282628 & NM_001155536 & 2 & 1104 & 367 & 6 \\
\hline$Z m Z I P 4$ & LOC100280287 & HM048832 & 4 & 1161 & 386 & 6 \\
\hline ZmZIP5 & LOC100281339 & NM_001154257 & 6 & 1209 & 402 & 6 \\
\hline ZmZIP6 & LOC100283249 & NM_001156151 & 8 & 1191 & 396 & 8 \\
\hline$Z m Z I P 7$ & LOC100284121 & NM_001157018 & 6 & 1164 & 387 & 6 \\
\hline$Z m Z I P 8$ & LOC100281849 & NM_001154769 & 7 & 1191 & 396 & 7 \\
\hline ZmIRT1 & LOC100285748 & NM_001158638 & 1 & 1146 & 381 & 8 \\
\hline
\end{tabular}

${ }^{\mathrm{a}}$ The Gene ID from MaizeGDB.

${ }^{\mathrm{b}} \mathrm{CDS}$ of each predicted gene sequence was obtained from Genbank by BLAST search. 


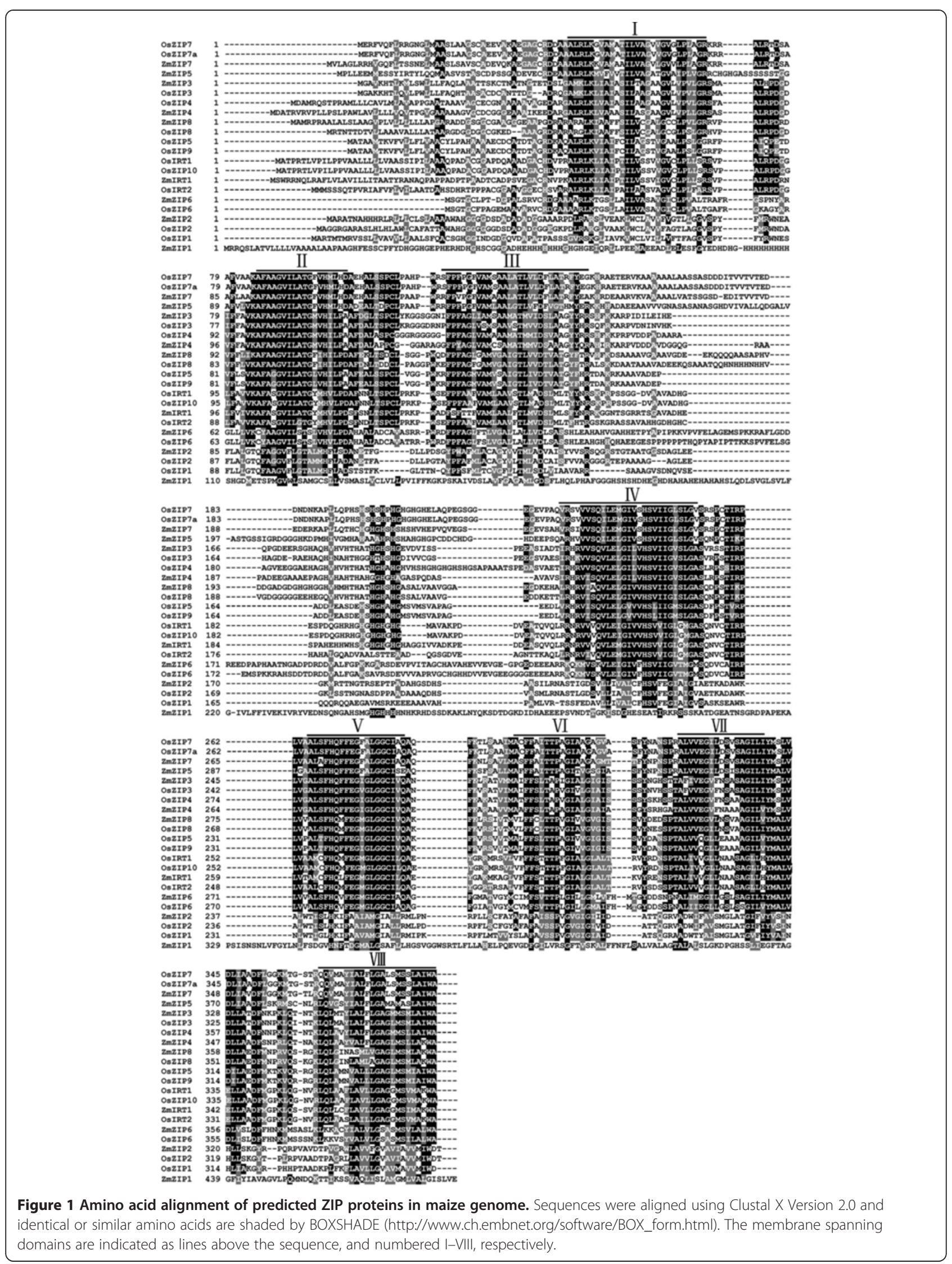


Figure 2 Phylogenetic analysis of the ZIP family members from various species. The unrooted phylogenetic tree was constructed with the deduced protein sequences of ZIP proteins from various species using the neighbor-joining method in MEGA 4.0 software. For proteins and accession numbers used for phylogenetic analysis, refer to Methods. The ZmZIP proteins are boxed, and the scale bar corresponds to a distance of 20 changes per 100 amino acid positions.

ZmZIP5 may be essential for both embryo and endosperm development.

\section{Subcellular localization of ZmZIPs}

To study the localization of ZmZIP proteins, the full-length coding regions without termination codons of the ZmZIP genes were $\mathrm{C}$-terminal fused with green fluorescent protein (GFP) and the fusion proteins were expressed under cauliflower mosaic virus $35 \mathrm{~S}$ promoter. The ZmZIPs-GFP fusion proteins were transiently expressed in Arabidopsis mesophyll protoplasts and onion epidermal cells. The green fluorescence was visualized by confocal microscopy. As showed in Figure 5 and Additional file 4, all ZmZIP proteins were localized to the plasma membrane and endomembrane system, which was further identified as endoplasmic reticulum (ER) by co-localization with an ER marker in Arabidopsis mesophyll protoplasts (Figure 5). In addition, the GFP signal can be observed at the border of the cell, indicating the plasma membrane localization of ZmZIPs (Additional file 4). Moreover, plasmolysis was performed to further confirm the plasma membrane localization (Additional file 5). Cells expressing GFP were used as controls, which showed green fluorescence in nucleus and cytoplasm.

\section{Complementation in yeast cells}

The yeast complementation analysis was performed in order to test whether ZmZIPs possess the capacity of transporting $\mathrm{Zn}$ or $\mathrm{Fe}$ in organisms. Although, it was demonstrated that $\mathrm{Mn}$ is a potential substrate for ZIPs $[22,33,34]$, it has not been tested in this study. The full-length cDNAs of ZmZIP genes were expressed in the Saccharomyces cerevisiae zrt1zrt2 double mutant (ZHY3) and fet3fet4 double mutant (DEY1453). The transformed ZHY3 expressing ZmZIP genes were grew on SD media plus $0.4 \mathrm{mM}$ EDTA. The result showed that the expression of ZmIRT1 protein remarkably reversed this growth defect in the yeast mutant, while other ZmZIPs reversed this growth defect as efficiently as the functional characterized ZIP proteins, OsZIP5 and OsZIP8 (Figure 6A). To test the iron transporter activity, the yeast mutants DEY1453 transformed with pFL61-ZmZIPs were grown on SD media plus $50 \mathrm{mM}$ MES. The result revealed that ZmIRT1 reversed the growth defect significantly, while the effect of other proteins were relatively inferior, though 


\begin{tabular}{|c|c|c|c|c|}
\hline है & 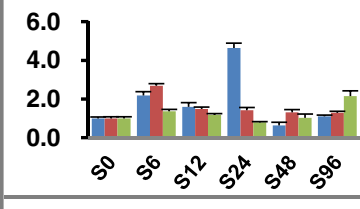 & 0.0 & $\begin{array}{l}6.0 \\
4.0 \\
2.0 \\
0.0\end{array}$ & $\left.\begin{array}{l}3.0 \\
2.0 \\
0.0\end{array}\right]$ \\
\hline$\underset{\substack{\text { N } \\
\text { N }}}{\text { N }}$ & $\begin{array}{l}3.0 \\
1.0 \\
0.0\end{array}$ & $\begin{array}{l}3.0 \\
2.0 \\
1.0 \\
0.0\end{array}$ & $\begin{array}{l}3.0 \\
1.0 \\
0.0\end{array} \frac{5^{0} 5^{6} 5^{2} 5^{20} 5^{60} 5^{60}}{}$ & 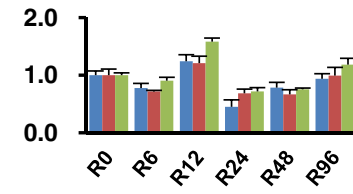 \\
\hline$\underset{\substack{\text { N } \\
\text { N }}}{ }$ & $\begin{array}{l}10.0 \\
0.0 \\
0.0\end{array}$ & 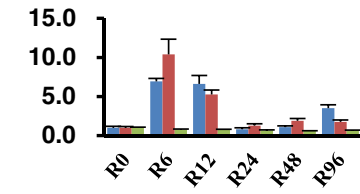 & 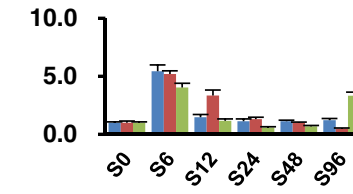 & 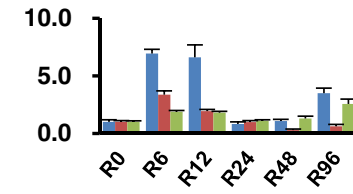 \\
\hline 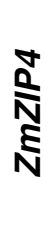 & $\begin{array}{ll}6.0 \\
0.0 \\
0.0\end{array}$ & $\begin{array}{l}1.5 \\
1.0 \\
0.5 \\
0.0\end{array}$ & $\begin{array}{l}8.0 \\
4.0 \\
2.0 \\
0.0\end{array}$ & $\left.\begin{array}{l}3.0 \\
2.0 \\
1.0 \\
0.0\end{array}\right]$ \\
\hline$\underset{\substack{N \\
\text { N }}}{\stackrel{n}{N}}$ & {$\left[\begin{array}{l}10.0 \\
5.0 \\
0.0\end{array}\right.$} & $\left.\begin{array}{l}3.0 \\
2.0 \\
1.0 \\
0.0\end{array}\right]$ & $\begin{array}{l}6.0 \\
4.0 \\
2.0 \\
0.0\end{array}$ & $\left.\begin{array}{l}6.0 \\
4.0 \\
2.0 \\
0.0\end{array}\right]$ \\
\hline$\underset{\substack{N \\
\Sigma}}{\mathbb{N}}$ & $\begin{array}{l}3.0 \\
2.0 \\
1.0 \\
0.0\end{array}$ & $\begin{array}{l}3.0 \\
2.0 \\
1.0 \\
0.0\end{array}$ & 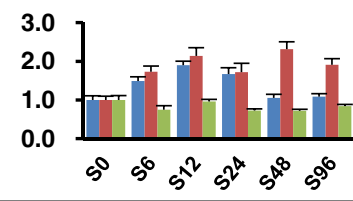 & 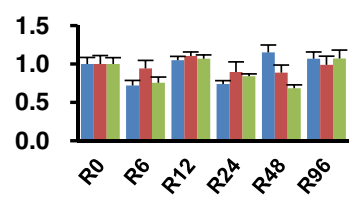 \\
\hline$\underset{\substack{\hat{N} \\
\text { N }}}{\mathrm{N}}$ & 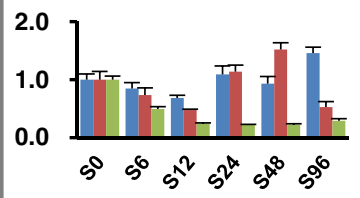 & $\begin{array}{l}1.5 \\
0.0 \\
0.0\end{array}$ & 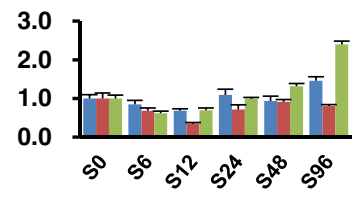 & $\left.\begin{array}{l}3.0 \\
1.0 \\
0.0\end{array}\right]$ \\
\hline$\underset{\substack{N \\
\text { N } \\
\text { N }}}{\infty}$ & $\begin{array}{l}10.0 \\
5.0 \\
0.0\end{array}$ & 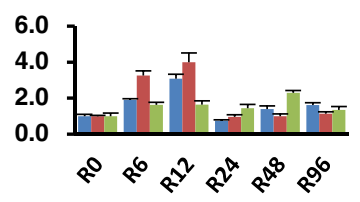 & $\begin{array}{l}6.0 \\
2.0 \\
0.0\end{array} \frac{5^{0} 5^{2} s^{20} 5^{20} 5^{60}}{5^{6}}$ & 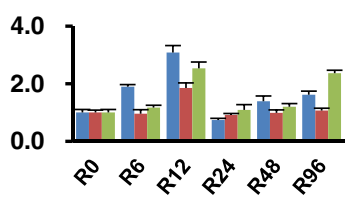 \\
\hline 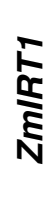 & 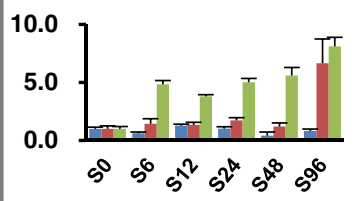 & 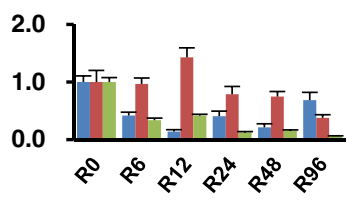 & 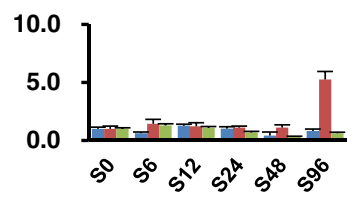 & $\left.\begin{array}{l}15.0 \\
10.0 \\
5.0 \\
0.0\end{array}\right]$ \\
\hline & e $\mathbf{3}$ (See legend on next page.) & - $\quad \mathbf{Z n}++$ & $\square \mathbf{C K}$ & Fe++ \\
\hline
\end{tabular}


(See figure on previous page.)

Figure 3 Expression patterns of the nine ZmZIP genes in maize seedlings under various metal conditions. Two-week old shoots (S) and roots (R) of maize seedlings, under standard nutrient condition (CK), Zn, Fe-deficiency (Zn-), (Fe-), $200 \mu \mathrm{M} \mathrm{ZnSO} \mathrm{Zn}_{4}(\mathrm{Zn++}$ ) and $500 \mu \mathrm{M} \mathrm{FeSO}$ ( Fe++) treated, were harvested respectively at 0 h, 6 h, 12 h, 24 h, 48 h, 96 h after treatment. Relative mRNA abundance of each gene was normalized with ZmActin 1 gene. Data from real-time RT-PCR experiments were analyzed according to the $2^{-\Delta \Delta \mathrm{Ct}}$ method. The error bars indicate standard deviations.

that was as efficiently as a reported iron transporter OsIRT1 (Figure 6B). It was interesting to find that the yeast mutants expressing ZmIRT1 showed the strongest propagation under both $\mathrm{Zn}$ - and Fe-limited conditions (Figure 6A and 6B), indicating that ZmIRT1 may be essential for $\mathrm{Zn}$ and Fe translocation during maize growth.
In addition, except for ZmIRT1, other ZmZIP proteins can complement the iron transporter mutant fet3fet 4 at high $\mathrm{pH}$ but weakly at low $\mathrm{pH}$ conditions (Additional file 6). Thus, the ZmZIP genes identified in this study encoded functional $\mathrm{Zn}$ or Fe transporter, and ZmIRT1 may play a dominant role in ion translocation in maize.
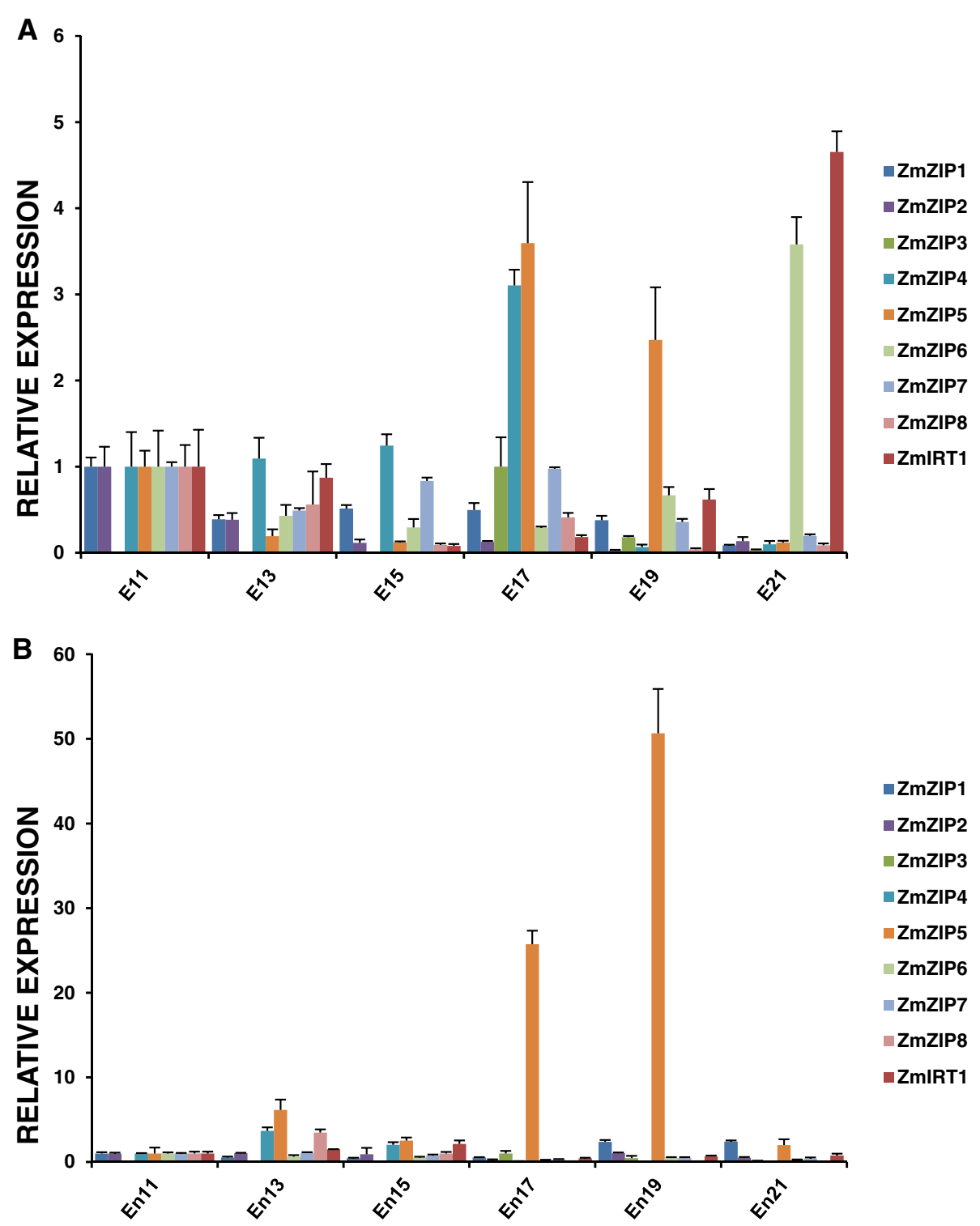

Figure 4 Expression patterns of the nine ZmZIP genes during embryo and endosperm development. The developing embryo (E) and endosperm (En) were obtained on indicated days after pollination (11 DAP, 13 DAP, 15 DAP, 17 DAP, 19 DAP and 21 DAP). The relative mRNA abundance of each gene in embryo (A) and endosperm (B) was normalized with ZmActinl gene. Data from real-time RT-PCR experiments were analyzed according to the $2^{-\Delta \Delta C t}$ method. The error bars indicate standard deviations. 


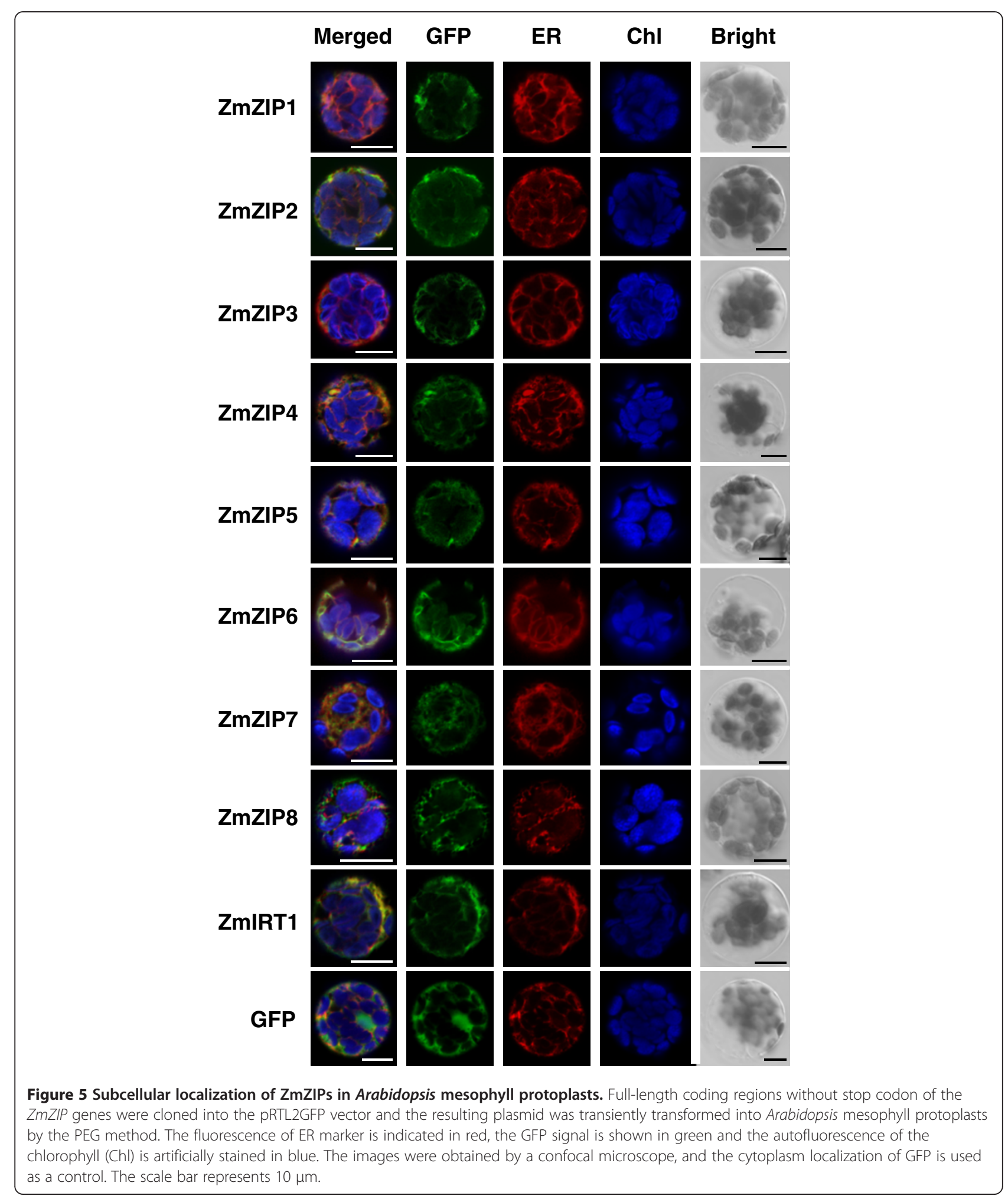

\section{Discussion}

The ZIP genes have been reported in several plants, including Arabidopsis, rice, Medicago truncatula, wild emmer wheat, Vitis vinifera L and barley [18-22,24-29,32,33,35-45].
Most of these genes are found to function as $\mathrm{Zn}$ or $\mathrm{Fe}$ transporter, though some ZIPs have major roles in $\mathrm{Mn}$ transport $[22,33,34]$. Members of the ZIP family have eight predicted transmembrane (TM) domains and a 


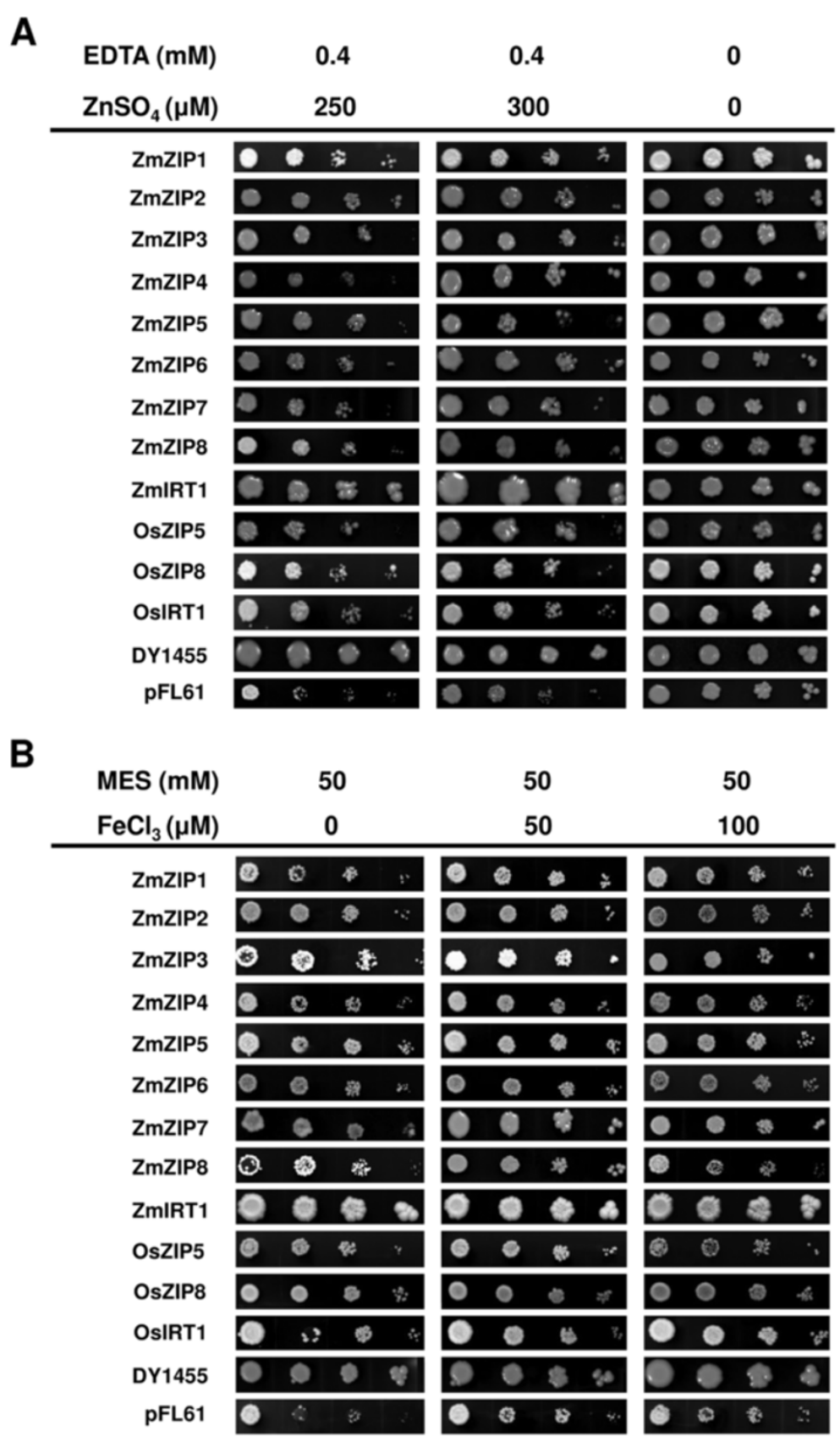

Figure 6 Functional complementation in yeast mutant strains. The Zn and Fe transportation mutant zrt1zrt2 (A) and fet3fet4 (B) were transformed with the expression vector pFL61 carrying ZmZIP1-ZmZIP8, ZmIRT1 and the functional characterized ZIP genes, OsZIP5, OsZIP8 and OsIRT1. The wild type strain DY1455 transformed with pFL6 was applied as a positive control, and the yeast mutant transformed with empty vector pFL61 was used as a negative control. The transformed yeast cells were grown under different metal conditions as indicated, and the transformed fet3fet4 was grown on medium with $\mathrm{pH}$ 5.8. Cell concentration was adjusted to $\mathrm{OD}_{600}=1$ and serial dilutions $(1.0,0.1,0.01$ and 0.001 ) were made. For assay, $5-\mu \mathrm{L}$ of each dilution was spotted on plates and grown for 6 days at $30^{\circ} \mathrm{C}$.

variable region between TM-3 and TM-4 where contains a potential metal-binding domain [15]. Although ZIPs have been characterized in many plants, to the best of our knowledge, there were few reports concerning the isolation and functional characterization of ZIPs in maize. Since, the maize genome sequencing project was completed, many gene families have been identified and characterized in maize [46-48]. In this study, nine cDNAs encoding ZmZIP genes were obtained from maize based on amino acids sequences similarity. In order to analyze the evolutionary 
relationship of the ZIP family, a phylogenetic tree consists of nine ZIPs and one ZLP1 from maize, 14 rice ZIPs (OsZIPs), 16 Arabidopsis ZIPs (AtZIPs), 5 Hordeum vulgare ZIPs (HvZIPs), 7 Medicago truncatula ZIPs (MtZIPs), Wild Emmer Wheat ZIP (TdZIP1), and Glycine max ZIP (GmZIP1) was generated (Figure 2). It was revealed that the predicted amino acid sequences of ZmZIPs were closely related to ZIPs from other plant species and they were existed as orthologs (ZmIRT1 and HvIRT1, ZmZIP1 and OsIAR1, ZmZIP2 and OsZIP2, ZmZIP3 and OsZIP3, ZmZIP4 and OsZIP4, ZmZIP6 and OsZIP6, ZmZIP7 and OsZIP7, ZmZIP8 and OsZIP8), indicating that those ZIPs from maize, rice and barley may share a common evolutionary ancestor. It has been reported that OsZIP4, OsZIP5 and OsZIP8 are functional zinc transporters and localized to the plasma membrane $[27,32,36]$. AtIRT2 is an iron transporter and localized to intracellular vesicles, suggesting an essential role in preventing metal toxicity through compartmentalization and remobilize iron stores from internal storage vesicles [40]. All of these proteins are able to complement the growth of the yeast strain ZHY3 or DEY1453, which is sensitive to $\mathrm{Zn}$ or Fe deprivation due to the mutation in both high and low $\mathrm{Zn}$ or Fe affinity system. In this study, similar to the Arabidopsis and rice ZIPs, the maize ZIP proteins showed different degree of zinc or iron complementary capabilities (Figure 6A and 6B). Moreover, ZmZIPs were localized to the plasma membrane and endoplasmic reticulum (Figure 5), suggesting they may functional related to excessive ion detoxification. Hence, these results demonstrated that ZmZIP genes encode $\mathrm{Zn}$ or Fe transporters and have various functions associated with uptake and translocation, detoxification and storage of $\mathrm{Zn}$ or Fe in plant cells.

The expression patterns of ZmZIP genes reflect their diverse functions during $\mathrm{Zn}$ or Fe translocation. It has been reported that the ZIP genes displayed various expression profiles regarding tissue specificity and response to fluctuating environmental $\mathrm{Zn}$ and Fe conditions. For example, OsZIP7a was induced mainly in Fe-deficient roots, while OsZIP8 was stimulated in $\mathrm{Zn}$-deficient shoots and roots [41]. Histochemical localization analysis showed that the mRNA of OsZIP4 was accumulated in the vascular bundles of leaves and roots, phloem cells of the stem and the meristems [36]. In the model legume Medicago truncatula, the expression of MtZIP2 was detected in roots and stems and was induced by Zn deficiency [49], likewise $M t Z I P 1$ was expressed in $Z n$-deficient roots and leaves [37]. In our study, the expression of ZmIRT1 was remarkably up-regulated in roots and shoots under Fe-deficiency, and was induced in shoots at $96 \mathrm{~h}$ after Zn-deficiency (Figure 3). ZmZIP4, 5, 7 and 8 were induced and reached a peak in shoots and roots at $96 \mathrm{~h}$ after Fe-excess (Figure 3). These results suggested that ZmIRT1 may play essential roles in $\mathrm{Fe}$ and $\mathrm{Zn}$ uptake, especially under iron deficiency, while $Z m Z I P 4,5,7$ and 8 may associate with detoxification and storage of excessive Fe. Previous study showed that Arabidopsis thaliana transcription factors bZIP19 and bZIP23 regulate the adaptation to zinc deficiency by increase the transcription of ZIPs and other genes [50]. Therefore, maize bZIP-like transcription factors may be essential for the regulation of $Z m Z I P$ expression under $\mathrm{Zn}$ deficient status.

It has been demonstrated that $\mathrm{Zn}$ play essential roles in embryo and endosperm development [2-4]. Therefore, the $Z m Z I P$ genes that preferentially expressed in embryo and endosperm may be important for translocation of $\mathrm{Zn}^{2+}$ into sink organs. The expression analysis showed that ZmIRT1, ZmZIP4 and ZmZIP6 were mainly expressed in embryo, while $Z m Z I P 5$ was expressed in both embryo and endosperm. The accumulations of ZmZIP4 and ZmZIP5 were up-regulated in the middle stages of embryo development and then they were repressed, suggesting that they may be essential for plumule and radicle growth. In contrast, ZmIRT1 and ZmZIP6 were stimulated in the late development stages of embryo, which indicates that they may associate with the maturation of embryo. Interestingly, it was observed that the accumulation of ZmZIP5 was dramatically up-regulated during the development of endosperm and reached a peak on 19 DAP, though its expression was decreased on 21 DAP, which suggests that ZmZIP5 may involve in the accumulation of nutrient substance at early grain filling stage. By the light of well assembled genome sequence of maize, an in silico promoter analysis was performed for those ZmZIP genes preferentially expressed in embryo and endosperm. The results showed that the ZmIRT1, ZmZIP4, ZmZIP5 and ZmZIP6 contain cis-elements for seed expression (Additional file 7). Considering that there was some correlation between the VvZIP3 expression profile and the $\mathrm{Zn}$ accumulation pattern during the development of reproductive organs [42], we assumed that ZmIRT1, ZmZIP4, ZmZIP5 and ZmZIP6 may play various roles in both embryo and endosperm development.

Enhancing the iron and zinc content in cereal grains is important for improving human nutrition. Since the amount of metal transporter is generally rate-limiting [39], manipulating the transporters involved in translocation of micro-essential metals into sink organs could be a way to increase mineral contents. For instance, overexpressing AtZIP1 in barley resulted in a rise in the short-term zinc uptake as well as higher seed $\mathrm{Zn}$ and Fe contents [39]. Likewise, the iron and zinc contents were elevated in the shoots, roots and mature seeds of transgenic rice constitutively overexpressing OsIRT1 [26]. However, overexpressing OsZIP4 under the control of the cauliflower mosaic virus (CaMV) 35S promoter lead to $\mathrm{Zn}$ accumulation in roots, while the $\mathrm{Zn}$ concentration in seeds were four times lower than untransgenic controls [28]. Moreover, overexpressing 
OsZIP5 and OsZIP8 in rice under the control of the maize ubiquitin promoter lead to increased $\mathrm{Zn}$ level in roots, though that in shoots and mature seeds were reduced in the transgenic plants $[27,32]$. These results indicate that ectopic overexpression of ZIP proteins may have little effect on the enhancement of $\mathrm{Zn}$ content in seeds due to overproduction of ZIP in vegetative tissues. Therefore, increasing the accumulation of ZIP proteins and maintain their expression pattern may provide an alternative way to enhance $\mathrm{Zn}$ or Fe contents. Since it was revealed that the expression of ZmIRT1, ZmZIP4, ZmZIP5 and ZmZIP6 are associated with seed development, it can be assumed that overexpression of these ZIP genes in a seed specific manner may provide an alternative strategy for biofortification of crops with $\mathrm{Zn}$ and Fe.

\section{Conclusions}

Although zinc and iron are essential micronutrients for plant growth and development, functional analysis of ZIP family in maize is still limited. The present study provides relevant information concerning the identification and functional characterization of ZmZIP family, and suggests that they may involve in metal uptake and overall cell zinc homeostasis. It is also indicated that $Z m Z I P s$ may be essential for ion translocation and storage during differential stages of embryo and endosperm development. In the present study, we provided detailed information of the evolutionary relationship and putative functional divergence of the $Z m Z I P$ gene family during the growth and development of maize.

\section{Methods}

\section{Plant growth}

Zea mays seeds were cultured in vermiculite (irrigated with Hoagland nutrient solution) in climate chambers with a light/dark cycle of 16/8 h. The 13-day-old seedlings were transferred to the Hoagland nutrient solution grown for 6 days (The standard Hoagland nutrient solution contained $2.0 \mu \mathrm{M} \mathrm{ZnSO}, 50 \mu \mathrm{M}$ Fe(III)-EDTA, $0.5 \mu \mathrm{M} \mathrm{CuSO}_{4}$, and $2.0 \mu \mathrm{M} \mathrm{MnSO}$ ), then transferred to the standard Hoagland nutrient solution and Hoagland medium lacking $\mathrm{ZnSO}_{4}$ (Zn-deficient), Fe (III)-EDTA (Fe- deficient), and $200 \mu \mathrm{M} \mathrm{ZnSO}_{4}$ (Zn-excess), $500 \mu \mathrm{M}$ Fe(III)-EDTA (Fe-excess). Shoots and roots were selected and detached at $0 \mathrm{~h}, 6 \mathrm{~h}, 12 \mathrm{~h}, 24 \mathrm{~h}, 48 \mathrm{~h}$ and $96 \mathrm{~h}$ after the different treatment for real-time RT-PCR assays.

\section{Bioinformatics analysis}

The BLAST program at GenBank (http://www.ncbi. nlm.nih.gov/blast) was used to search the maize ZIP cDNAs and the acquired cDNAs were compared to the corresponding genome database from maizesequence (http://maizesequence.org/index.html). The putative amino acid sequences were aligned with the program Clustal $\mathrm{X}$
Version 2.0 [51] and colored by BOXSHADE (http://www. ch.embnet.org/software/BOX_form.html). Potential transmembrane domains in protein sequences were identified using TMHMM [52]. The phylogenetic tree of 54 members of the ZIP proteins from various species was constructed using MEGA version 4.0 [53]. The accession numbers for the proteins are as follows: Arabidopsis thaliana (AtZIP1: AAC24197, AtZIP2: AAC24198, AtZIP3: AAC24199, AtZIP4: AAB65480, AtZIP5: AAL38432, AtZIP6: AAL38433, AtZIP7: AAL38434, AtZIP8: AAL83293, AtZIP9: AAL38435, AtZIP10: AAL38436, AtZIP11: AAL67953, AtZIP12: AAL38437, AtIRT1: AAB01678, AtIRT2: NP_001031670, AtIRT3: NP_564766, AtIAR1: AF216524); Oryza sativa (OsIAR1: NP_001062003, OsIRT1: AB070226, OsIRT2: AB126086, OsZIP1: AY302058, OsZIP2: AY302059, OsZIP3: AY323915, OsZIP4: AB126089, OsZIP5: AB126087, OsZIP6: AB126088, OsZIP7: AB126090, OsZIP7a: AY275180, OsZIP8: AY324148, OsZIP9: AY281300, OsZIP10: AK107681); Zea mays (ZmZIP1: NM_001137726, ZmZIP2: NM_001159169, ZmZIP3: NM_001155536, ZmZIP4: HM048832, ZmZIP5: NM_001154257, ZmZIP6: NM_001156151, ZmZIP7: NM_001157018, ZmZIP8: NM_001154769, ZmIRT1: NM_001158638, ZmZLP1: ACO50388); Hordeum vulgare (HvIRT1: EU545802, HvZIP3: FJ208991, HvZIP5: FJ208992, HvZIP7: AM182059, HvZIP8: FJ208993); Medicago truncatula (MtZIP1: AY339054, MtZIP2: AY007281, MtZIP3: AY339055, MtZIP4: AY339056, MtZIP5: AY339057, MtZIP6: AY339058, MtZIP7: AY339059); Wild Emmer Wheat (TdZIP1:AY864924); Glycine max (GmZIP1: AY029321).

\section{RNA isolation and real-time RT-PCR}

Total RNA was isolated from shoots and roots with TRIzol (Takara). For cDNA synthesis, we used $4 \mu \mathrm{g}$ of total RNA as a template and M-MLV reverse transcriptase (Fermentas) by primering with oligo-d $(\mathrm{T})_{18}$ in a $40-\mu \mathrm{L}$ reaction mixture. Real-time RT-PCR was performed in a $20-\mu \mathrm{L}$ solution containing a $5-\mu \mathrm{L}$ aliquot of the cDNA, $0.4 \mu \mathrm{M}$ of gene-specific primers (Additional file 8) and $10-\mu \mathrm{L}$ SYBR Green I (Takara). The fragment was amplified by PCR in an ABI 7500 Real Time Thermal Cycler. The constitutively expressed ZmActin1 gene [GenBank: J01238.1] was amplified as the reference gene using the primers ZmActin1F and ZmActin1R (Additional file 8). Changes in expression were calculated via the $\Delta \Delta \mathrm{Ct}$ method [54]. For all real-time RT-PCR analysis, two biological replicates were used and three technical replicates were performed for each biological replicate. The sizes of the amplified fragments were confirmed by gel electrophoresis.

\section{Cloning of target genes}

The cDNA sequences of nine putative maize ZIP genes with a complete ORF were obtained from the MaizeSequence database (http://www.maizesequence.org/). The primers (Additional file 8) were designed for amplifying the ORFs 
of these nine ZmZIP genes. Total RNA was isolated from shoots with TRIzol (Takara), and was treated with DNaseI (NEB) before being reverse transcribed. For cDNA synthesis, we used $2 \mu \mathrm{g}$ of total RNA as a template and M-MLV reverse transcriptase (Fermentas) by primering with oligo-d $(\mathrm{T})_{18}$ in a $20-\mu \mathrm{L}$ reaction mixture. PCR was performed in a $20-\mu \mathrm{L}$ solution containing a $5-\mu \mathrm{L}$ aliquot of the cDNA, $10 \mu \mathrm{M}$ of gene-specific primers (Additional file 8), $0.5 \mathrm{U} \mathrm{Ex}$ Taq polymerase (Takara), $8 \mathrm{mM}$ dNTPs, $10-\mu \mathrm{L}$ of $2 \times \mathrm{GCI}$ buffer. PCR was performed on a DNA amplification machine (BIO RAD) for a denaturation of $4 \mathrm{~min}$ at $94^{\circ} \mathrm{C}$, followed by 33 cycles of $1 \mathrm{~min}$ at $94^{\circ} \mathrm{C}, 1 \mathrm{~min}$ at $60^{\circ} \mathrm{C}$, and $1 \mathrm{~min}$ at $72^{\circ} \mathrm{C}$ and a final extension of $10 \mathrm{~min}$ at $72^{\circ} \mathrm{C}$. The PCR products were separated on a $1 \%$ agarose gel and purified with Gel DNA Purification Kit (Shenergy Biocolor) according to the manufacturer's instruction. The purified product was then cloned into the pGEM-T easy vector (Promega, USA) and sequenced (Openlab, China).

\section{Subcellular localization}

For subcellular localization, a C-terminal GFP fusion expression vector pRTL2GFP was used [48]. Gene-specific primers were designed and the stop codons were deleted (Additional file 8). The coding regions without the stop codon were cloned into pRTL2GFP, respectively. The plasmids were purified using the Wizard Plus Miniprep DNA Purification System (Promega). The ZmZIP-GFP fusion constructs and the mcherry labeled ER marker were co-transformed into Arabidopsis mesophyll protoplasts as described previously $[55,56]$. After incubation in the dark at $26^{\circ} \mathrm{C}$ for $14 \mathrm{~h}$, the fluorescence was examined using a confocal microscope (LSM700; Carl Zeiss). The GFP signal was excitated at $488 \mathrm{~nm}$, and the emission was collected at 500-530 $\mathrm{nm}$; the mcherry signal was excitated at $555 \mathrm{~nm}$, and the fluorescence emission was collected at $610 \mathrm{~nm}$; the 630 emission filter was used to observe the autofluorescence of chlorophyll.

\section{Yeast complementation}

The ORFs of ZmZIP genes were amplified with gene specific primers (Additional file 8), and the PCR fragments were purified from an agarose gel and subsequently ligated into the NotI site of the yeast expression vector pFL61 (provided from Dr. David Eide, University of Missouri-Columbia) [57]. The resulting constructs were sequenced to ensure the correct orientations of the inserts and sequences. The yeast strains used in this experiment are zrt1zrt2 ZHY3 (MATo ade6 can1 his3 leu2 trp1 ura3 zrt1::LEU2 zrt2::HIS3), fet3fet4 DEY1453 (MATa/MATa ade2/+ can1/can1 his3/his3 leu2/leu2 trp1/trp1 ura3/ura3 fet3-2::HIS3/fet3-2::HIS3 fet4-1::LEU2/fet4-1::LEU2), and DY1455 (MATa ade6 can1 his3 leu2 trp1 ura3) (provided by Dr. David Eide) $[58,59]$. The pFL61-ZmZIPs were transformed into the yeast strains ZHY3 and DEY1453 using the electroporation method. The empty vector pFL61was applied as a negative control, OsIRT1 was used as the positive control for iron transporter, OsZIP5 and OsZIP8 were applied as the positive control for zinc transporter, and the wild type strain DY1455 harbouring pFL61 was used as another positive control. The yeast complementation was performed as described previously [22] with slight modification. Transformed cells were selected on synthetic agar medium (SD) containing amino acid supplements without Uracil and $2 \%$ glucose. In growth-test experiments, $5-\mu \mathrm{L}$ drops of yeast culture at an optical density of 1.0, 0.1, 0.01 and 0.001 were spotted onto medium. The yeast strain of zrt1zrt2 ZHY3 were grown on SD/-ura medium ( $\mathrm{pH} 4.4$ ) supplemented with 0.4 mM EDTA and $250 \mu \mathrm{M}$ or $300 \mu \mathrm{M} \mathrm{ZnSO}_{4}$. The yeast strain of fet 3 fet 4 were grown on $\mathrm{SD} /$-ura medium ( $\mathrm{pH} 5.5,5.8$ containing $50 \mathrm{mM} 2$ (N-morpholino) ethanesulfonic acid (MES) supplemented with 0,50 or $100 \mu \mathrm{M} \mathrm{FeCl}$.

\section{Additional files}

Additional file 1: Amino acid alignment of ZmIRT1 with other IRT proteins. Sequences were aligned using Clustal X Version 2.0 and the identical or similar amino acids are shaded by BOXSHADE (http://www. ch.embnet.org/software/BOX_form.html). The residue D100 in ZmIRT1 is marked with an asterisk.

Additional file 2: Expression patterns of the nine ZmZIP genes in maize seedlings. The shoots $(S)$ and roots $(R)$ of two weeks old hydroponically cultured maize seedlings in Hoagland nutrient solution were harvested, respectively. Relative mRNA abundance of each gene was normalized with ZmActin1 gene. Data from real-time RT-PCR experiments were analyzed according to the $2^{-\Delta \Delta C \mathrm{Ct}}$ method. The error bars indicate standard deviations.

Additional file 3: Expression patterns of the nine ZmZIP genes in maize under $\mathbf{C u}$-, $\mathbf{M n}$ - deficiency. Two-week old shoots (S) and roots (R) of maize seedlings, under $\mathrm{Cu}-$, Mn-deficiency treated (Cu-), (Mn-) were harvested respectively at 0 h, 6 h, 12 h, 24 h, 48 h and 96 h. Relative mRNA abundance of each gene was normalized with ZmActin 1 gene. Data from real-time RT-PCR experiments were analyzed according to the $2^{-\Delta \Delta C \mathrm{t}}$ method. The error bars indicate standard deviations.

Additional file 4: Subcellular localization of ZmZIPs in onion epidermal cells. Full-length coding regions without stop codon of the ZmZIP genes were cloned into the PRTL2GFP vector and the resulting plasmid was transiently transformed into onion epidermal cells by bombardment. The fluorescence was observed using a confocal laser scanning microscopy. GFP was imaged using $488 \mathrm{~nm}$ excitation and a 500-530 $\mathrm{nm}$ bandpass emission filter. The scale bar represents $100 \mu \mathrm{m}$.

Additional file 5: Subcellular localization of ZmZIP-GFP fusion proteins in plasmolyzed onion epidermal cells. The ZmZIP-GFP fusion proteins were transiently expressed in onion epidermal cells by bombardment, and a set of representative images are shown. The plasmolysis was performed for $15 \mathrm{~min}$ in 30\% sucrose. The Z-stack of optical sections and single optical slice of GFP fluorescence are shown. The cytoplasm localization of GFP is used as a control. GFP was imaged using $488 \mathrm{~nm}$ excitation and a 500-530 $\mathrm{nm}$ bandpass emission filter. The scale bar represents $100 \mu \mathrm{m}$.

Additional file 6: Functional complementation of the Fe transportation yeast mutant by $Z$ ZmZIPs under different $\mathrm{pH}$ values. The Fe transportation mutant fet3fet 4 were transformed with the expression vector pFL61 carrying ZmZIP1-ZmZIP8, ZmIRT1 and the 
functional characterized ZIP genes, OsZIP5, OsZIP8, and OsIRT1. The transformed yeast cells were grown under different $\mathrm{pH}$ conditions (A) pH 5.5 and (B) pH 5.8. Cell concentration was adjusted to $\mathrm{OD}_{600}=1$ and serial dilutions (1.0, $0.1,0.01$ and 0.001 ) were made. For assay, $5-\mu \mathrm{L}$ of each dilution was spotted on plates and grown for 6 days at $30^{\circ} \mathrm{C}$

Additional file 7: Putative cis-elements in the 2-Kb upstream promoter region of translation start site in ZmZIP genes.

Additional file 8: Primers used in gene cloning, vector construction and real-time RT-PCR analysis.

\section{Abbreviations}

CaMV: Cauliflower mosaic virus; GFP: Green fluorescent protein; ER: Endoplasmic reticulum; ORF: Opening reading frame; RT: Reverse transcripts; TM: Transmembrane; ZIP: Zinc-regulated transporters, iron-regulated transporter-like protein.

\section{Competing interests}

The authors declare that they have no competing interests.

\section{Authors' contributions}

SZL and JTC participated in the design of the study. SZL performed the bioinformatics analysis, gene cloning, real-time RT-PCR and yeast complementation. XJZ analyzed the data and drafted the manuscript. YQH assisted in gene cloning and plasmid construction. LYZ and SJZ collected the tissues for temporal and spatial expression analysis. YFZ and JJG helped in bioinformatics analysis. JTC and RMC contributed to revisions of the manuscript. All authors read and approved the final manuscript.

\section{Acknowledgements}

We thank Dr. David Eide (Nutritional Science Program, University of Missouri, Columbia, USA) for providing the yeast strains DEY1453, ZHY3 and yeast expression vector pFL61; Dr. Dongtao Ren (College of Biological Sciences, China Agricultural University) for providing the ER-marker. This work was supported by the National Special Program for GMO Development of China (grant number 2008ZX08003-002).

\section{Author details}

'Department of Agronomy, Agricultural University of Hebei/Hebei Sub-center of Chinese National Maize Improvement Center, Baoding 071001, China. ${ }^{2}$ Department of Crop Genomics \& Genetic Improvement, Biotechnology Research Institute, Chinese Academy of Agricultural Sciences, Beijing 100081, China.

\section{Received: 5 December 2012 Accepted: 1 August 2013}

Published: 8 August 2013

\section{References}

1. Haydon MJ, Cobbett CS: Transporters of ligands for essential metal ions in plants. New Phytol 2007, 174(3):499-506.

2. Rhodes D, Klug A: Zinc fingers. Sci Am 1993, 268(2):56-59. 62-55.

3. Vallee BL, Auld DS: Zinc coordination, function, and structure of zinc enzymes and other proteins. Biochemistry 1990, 29(24):5647-5659.

4. Vallee BL, Falchuk KH: The biochemical basis of zinc physiology. Physiol Rev 1993, 73(1):79-118.

5. Cakmak I: Enrichment of cereal grains with zinc: agronomic or genetic biofortification? Plant Soil 2008, 302(1-2):1-17.

6. Briat JF, Lebrun M: Plant responses to metal toxicity. C R Acad Sci III 1999, 322(1):43-54.

7. Casterline JE, Allen LH, Ruel MT: Vitamin B-12 deficiency is very prevalent in lactating Guatemalan women and their infants at three months postpartum. J Nutr 1997, 127(10):1966-1972.

8. Påhlsson A-M: Toxicity of heavy metals $(\mathrm{Zn}, \mathrm{Cu}, \mathrm{Cd}, \mathrm{Pb})$ to vascular plants. Water, Air, and Soil Pollution 1989, 47(3-4):287-319.

9. Price $\mathrm{AH}$, Hendry GAF: Iron-catalysed oxygen radical formation and its possible contribution to drought damage in nine native grasses and three cereals. Plant Cell Environ 1991, 14(5):477-484.

10. Palmgren MG, Clemens S, Williams LE, Kramer U, Borg S, Schjorring JK, Sanders D: Zinc biofortification of cereals: problems and solutions. Trends Plant Sci 2008, 13(9):464-473.
11. Grotz N, Guerinot ML: Molecular aspects of $\mathrm{Cu}, \mathrm{Fe}$ and $\mathrm{Zn}$ homeostasis in plants. Biochim Biophys Acta 2006, 1763(7):595-608.

12. Kambe T, Yamaguchi-Iwai $Y$, Sasaki R, Nagao M: Overview of mammalian zinc transporters. Cell Mol Life Sci 2004, 61(1):49-68.

13. Taylor KM, Morgan HE, Johnson A, Nicholson RI: Structure-function analysis of HKE4, a member of the new LIV-1 subfamily of zinc transporters. Biochem J 2004, 377(Pt 1):131-139.

14. Colangelo EP, Guerinot ML: Put the metal to the petal: metal uptake and transport throughout plants. Curr Opin Plant Biol 2006, 9(3):322-330.

15. Guerinot ML: The ZIP family of metal transporters. Biochim Biophys Acta 2000, 1465(1-2):190-198.

16. Maser P, Thomine S, Schroeder JI, Ward JM, Hirschi K, Sze H, Talke IN, Amtmann A, Maathuis FJ, Sanders D, et al: Phylogenetic relationships within cation transporter families of Arabidopsis. Plant Physiol 2001, 126(4):1646-1667.

17. Eide $\mathrm{D}$, Broderius $\mathrm{M}$, Fett J, Guerinot ML: A novel iron-regulated metal transporter from plants identified by functional expression in yeast. Proc Natl Acad Sci U S A 1996, 93(11):5624-5628.

18. Henriques R, Jasik J, Klein M, Martinoia E, Feller U, Schell J, Pais MS, Koncz C: Knock-out of Arabidopsis metal transporter gene IRT1 results in iron deficiency accompanied by cell differentiation defects. Plant Mol Biol 2002, 50(4-5):587-597.

19. Varotto C, Maiwald D, Pesaresi P, Jahns P, Salamini F, Leister D: The metal ion transporter IRT1 is necessary for iron homeostasis and efficient photosynthesis in Arabidopsis thaliana. Plant J 2002, 31(5):589-599.

20. Vert G, Grotz N, Dedaldechamp F, Gaymard F, Guerinot ML, Briat JF, Curie C: IRT1, an Arabidopsis transporter essential for iron uptake from the soil and for plant growth. Plant Cell 2002, 14(6):1223-1233.

21. Nishida S, Tsuzuki C, Kato A, Aisu A, Yoshida J, Mizuno T: AtIRT1, the primary iron uptake transporter in the root, mediates excess nickel accumulation in Arabidopsis thaliana. Plant Cell Physiol 2011, 52(8):1433-1442.

22. Lin YF, Liang HM, Yang SY, Boch A, Clemens S, Chen CC, Wu JF, Huang JL, Yeh KC: Arabidopsis IRT3 is a zinc-regulated and plasma membrane localized zinc/iron transporter. New Phytol 2009, 182(2):392-404.

23. Kramer U, Talke IN, Hanikenne M: Transition metal transport. FEBS Lett 2007, 581(12):2263-2272

24. Bughio N, Yamaguchi H, Nishizawa NK, Nakanishi H, Mori S: Cloning an iron-regulated metal transporter from rice. J Exp Bot 2002, 53(374):1677-1682

25. Ishimaru Y, Suzuki M, Tsukamoto T, Suzuki K, Nakazono M, Kobayashi T, Wada Y, Watanabe S, Matsuhashi S, Takahashi M, et al: Rice plants take up iron as an $\mathrm{Fe}^{3+}$-phytosiderophore and as $\mathrm{Fe}^{2+}$. Plant $J$ 2006, 45(3):335-346.

26. Lee $\mathrm{S}$, An G: Over-expression of OsIRT1 leads to increased iron and zinc accumulations in rice. Plant Cell Environ 2009, 32(4):408-416.

27. Lee S, Jeong HJ, Kim SA, Lee J, Guerinot ML, An G: OsZIP5 is a plasma membrane zinc transporter in rice. Plant Mol Biol 2010, 73(4-5):507-517.

28. Ishimaru Y, Masuda H, Suzuki M, Bashir K, Takahashi M, Nakanishi H, Mori S, Nishizawa NK: Overexpression of the OsZIP4 zinc transporter confers disarrangement of zinc distribution in rice plants. J Exp Bot 2007, 58(11):2909-2915.

29. Durmaz E, Coruh C, Dinler G, Grusak M, Peleg Z, Saranga Y, Fahima T, Yazici A, Ozturk L, Cakmak I, et al: Expression and cellular localization of ZIP1 transporter under zinc deficiency in wild emmer wheat. Plant Molecular Biology Reporter 2011, 29(3):582-596.

30. Moreau S, Thomson RM, Kaiser BN, Trevaskis B, Guerinot ML, Udvardi MK, Puppo A, Day DA: GmZIP1 encodes a symbiosis-specific zinc transporter in soybean. J Biol Chem 2002, 277(7):4738-4746.

31. Xu Y, Wang B, Yu J, Ao G, Zhao Q: Cloning and characterisation of $Z m Z L P 1$, a gene encoding an endoplasmic reticulum-localised zinc transporter in Zea mays. Functional Plant Biology 2010, 37(3):194-205.

32. Lee S, Kim SA, Lee J, Guerinot ML, An G: Zinc deficiency-inducible OsZIP8 encodes a plasma membrane-localized zinc transporter in rice. Mol Cells 2010, 29(6):551-558.

33. Vert G, Briat JF, Curie C: Arabidopsis IRT2 gene encodes a root-periphery iron transporter. Plant J 2001, 26(2):181-189.

34. Milner MJ, Seamon J, Craft E, Kochian LV: Transport properties of members of the ZIP family in plants and their role in $\mathrm{Zn}$ and $\mathrm{Mn}$ homeostasis. J Exp Bot 2013, 64(1):369-381.

35. Ramesh SA, Shin R, Eide DJ, Schachtman DP: Differential metal selectivity and gene expression of two zinc transporters from rice. Plant Physiol 2003, 133(1):126-134. 
36. Ishimaru Y, Suzuki M, Kobayashi T, Takahashi M, Nakanishi H, Mori S, Nishizawa NK: OsZIP4, a novel zinc-regulated zinc transporter in rice. J Exp Bot 2005, 56(422):3207-3214.

37. Lopez-Millan AF, Ellis DR, Grusak MA: Identification and characterization of several new members of the ZIP family of metal ion transporters in Medicago truncatula. Plant Mol Biol 2004, 54(4):583-596.

38. Stephens BW, Cook DR, Grusak MA: Characterization of zinc transport by divalent metal transporters of the ZIP family from the model legume Medicago truncatula. Biometals 2011, 24(1):51-58.

39. Ramesh SA, Choimes S, Schachtman DP: Over-expression of an Arabidopsis zinc transporter in hordeum vulgare increases short-term zinc uptake after zinc deprivation and seed zinc content. Plant Mol Biol 2004, 54(3):373-385.

40. Vert G, Barberon M, Zelazny E, Seguela M, Briat JF, Curie C: Arabidopsis IRT2 cooperates with the high-affinity iron uptake system to maintain iron homeostasis in root epidermal cells. Planta 2009, 229(6):1171-1179.

41. Yang $X$, Huang J, Jiang $Y$, Zhang HS: Cloning and functional identification of two members of the ZIP (Zrt, Irt-like protein) gene family in rice (Oryza sativa L.). Mol Biol Rep 2009, 36(2):281-287.

42. Gainza-Cortes F, Perez-Diaz R, Perez-Castro R, Tapia J, Casaretto JA, Gonzalez S, Pena-Cortes H, Ruiz-Lara S, Gonzalez E: Characterization of a putative grapevine Zn transporter, VvZIP3, suggests its involvement in early reproductive development in Vitis vinifera L. BMC Plant Biol 2012, 12:111.

43. Pedas $P$, Schjoerring JK, Husted S: Identification and characterization of zinc-starvation-induced ZIP transporters from barley roots. Plant Physiol Biochem 2009, 47(5):377-383.

44. Narayanan NN, Vasconcelos MW, Grusak MA: Expression profiling of Oryza sativa metal homeostasis genes in different rice cultivars using a cDNA macroarray. Plant Physiol Biochem 2007, 45(5):277-286.

45. Sperotto RA, Boff T, Duarte GL, Santos LS, Grusak MA, Fett JP: Identification of putative target genes to manipulate $\mathrm{Fe}$ and $\mathrm{Zn}$ concentrations in rice grains. J Plant Physiol 2010, 167(17):1500-1506.

46. Lin YX, Jiang HY, Chu ZX, Tang XL, Zhu SW, Cheng BJ: Genome-wide identification, classification and analysis of heat shock transcription factor family in maize. BMC Genomics 2011, 12:76.

47. Xing H, Pudake RN, Guo G, Xing G, Hu Z, Zhang Y, Sun Q, Ni Z: Genome-wide identification and expression profiling of auxin response factor (ARF) gene family in maize. BMC Genomics 2011, 12:178.

48. Zhou X, Li S, Zhao Q, Liu X, Zhang S, Sun C, Fan Y, Zhang C, Chen R: Genome-wide identification, classification and expression profiling of nicotianamine synthase (NAS) gene family in maize. BMC Genomics 2013, 14(1):238.

49. Burleigh $\mathrm{SH}$, Kristensen BK, Bechmann IE: A plasma membrane zinc transporter from Medicago truncatula is up-regulated in roots by $\mathrm{Zn}$ fertilization, yet down-regulated by arbuscular mycorrhizal colonization. Plant Mol Biol 2003, 52(5):1077-1088.

50. Assuncao AG, Herrero E, Lin YF, Huettel B, Talukdar S, Smaczniak C, Immink RG, van Eldik M, Fiers M, Schat $H$, et al: Arabidopsis thaliana transcription factors bZIP19 and bZIP23 regulate the adaptation to zinc deficiency. Proc Natl Acad Sci U S A 2010, 107(22):10296-10301.

51. Thompson JD, Gibson TJ, Plewniak F, Jeanmougin F, Higgins DG: The CLUSTAL_X windows interface: flexible strategies for multiple sequence alignment aided by quality analysis tools. Nucleic Acids Res 1997, 25(24):4876-4882.

52. Krogh A, Larsson B, von Heijne G, Sonnhammer EL: Predicting transmembrane protein topology with a hidden Markov model: application to complete genomes. J Mol Biol 2001, 305(3):567-580.

53. Tamura K, Dudley J, Nei M, Kumar S: MEGA4: Molecular evolutionary genetics analysis (MEGA) software version 4.0. Mol Biol Evol 2007, 24(8):1596-1599.

54. Han MJ, Jung KH, Yi G, Lee DY, An G: Rice Immature Pollen 1 (RIP1) is a regulator of late pollen development. Plant Cell Physiol 2006, 47(11):1457-1472.

55. Yoo S-D, Cho Y-H, Sheen J: Arabidopsis mesophyll protoplasts: a versatile cell system for transient gene expression analysis. Nat Protocols 2007, 2(7):1565-1572.

56. Nelson BK, Cai X, Nebenfuhr A: A multicolored set of in vivo organelle markers for co-localization studies in Arabidopsis and other plants. Plant J 2007, 51(6):1126-1136.

57. Minet M, Dufour ME, Lacroute F: Complementation of Saccharomyces cerevisiae auxotrophic mutants by Arabidopsis thaliana cDNAs. Plant $J$ 1992, 2(3):417-422.
58. Zhao H, Eide D: The yeast ZRT1 gene encodes the zinc transporter protein of a high-affinity uptake system induced by zinc limitation. Proc Natl Acad Sci U S A 1996, 93(6):2454-2458.

59. Zhao $H$, Eide D: The ZRT2 gene encodes the low affinity zinc transporter in Saccharomyces cerevisiae. J Biol Chem 1996, 271(38):23203-23210.

doi:10.1186/1471-2229-13-114

Cite this article as: Li et al.: Identification and characterization of the zinc-regulated transporters, iron-regulated transporter-like protein (ZIP) gene family in maize. BMC Plant Biology 2013 13:114.

\section{Submit your next manuscript to BioMed Central and take full advantage of:}

- Convenient online submission

- Thorough peer review

- No space constraints or color figure charges

- Immediate publication on acceptance

- Inclusion in PubMed, CAS, Scopus and Google Scholar

- Research which is freely available for redistribution

Submit your manuscript at www.biomedcentral.com/submit
C Biomed Central 